\title{
The effect of metformin on ghrelin serum level in type $r$ diabetes mellitus
}

\author{
Mohammed Nabel Mohammed,Nahla O M Tawfik \\ Dept Dental Basic sciences, College of Dentistry, University of Mosul
}

$\frac{\text { Received }}{T \Lambda .0 . T \cdot 1 T} \quad \frac{\text { Accepted }}{T \Gamma . T \cdot T \cdot 1 T}$

ABSTRACT

Objectives: Ghrelin is an orexigenic peptide hormone. A great deal of evidence suggests that ghrelin is involved in the development of type $r$ diabetes mellitus (DM). The aim of this study was to investigate the effect of metformin on ghrelin serum level in type $r$ DM patients.

Patients and methods: This case control study was carried out in Al-Wafaa medical center for diabetic and endocrine disorder patients in Mosul from October $r .11$ to March $r \cdot \mid r$. In this study 00 type $r$ diabetic patients and $r \cdot$ control healthy subjects was participated. Those patients and subjects was divided into $\varepsilon$ groups. Blood samples had been collected from all subjects and patients and body mass index (BMI) had been calculated for each patient. Fasting blood sugar (FBS) level and ghrelin serum level were estimated for each patient.

Results: The study shows a non significant lower mean ghrelin serum level in control diabetic group in comparison to that of control healthy group. There is significant difference in ghrelin serum level between control diabetic patients group and diabetic patients' group using metformin $1 \cdots$ mg daily at $\mathrm{P}<\cdot .0$. Ghrelin serum level has a negative correlation with ages more than $r \cdot$ years old and BMI in both healthy and diabetic individuals.

Conclusion: Ghrelin serum level in diabetic patients is tends to be lower when compared with healthy subjects. Metformin increase ghrelin serum level in diabetic patients and this increment was related to the dose and duration.

Keywords: Diabetes, Ghrelin, Metformin.

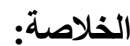

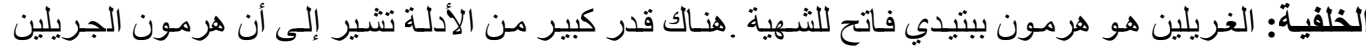

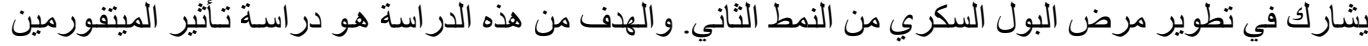

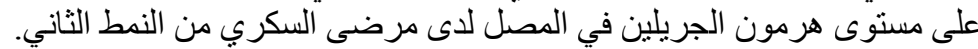

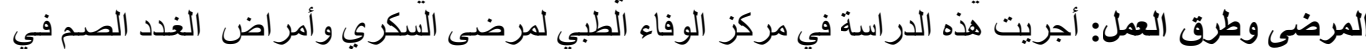

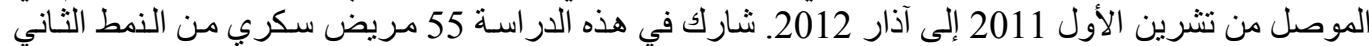

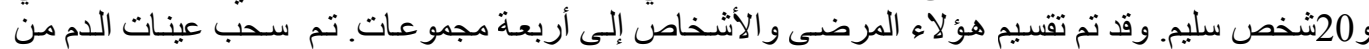

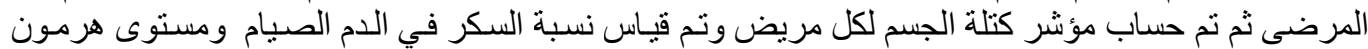

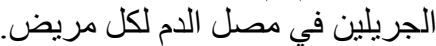

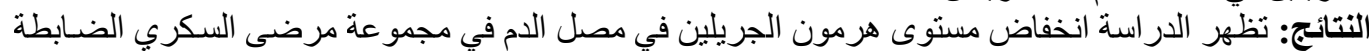

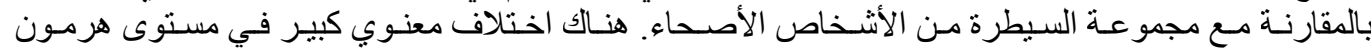

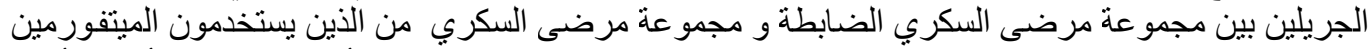

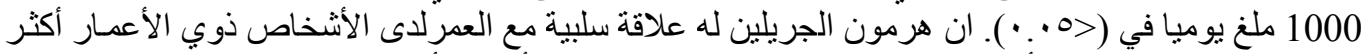

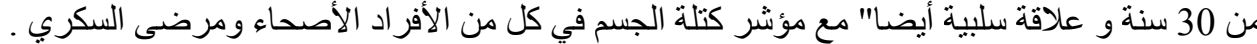

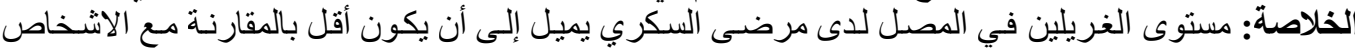

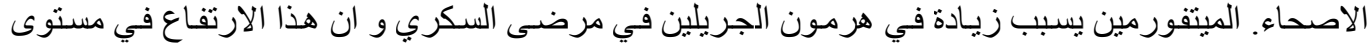
الجريلين يزداد مع زيادة جر عة الميتفورمين و مدة تعاطيه. 
D iabetes mellitus is a group of diseases characterized by an elevated blood glucose level (hyperglycaemia) resulting from defects in insulin secretion, in insulin action, or both. Diabetes mellitus is not a pathogenic entity but a group of etiologically different metabolic defects'. Type $r$ diabetes mellitus is the most common form of diabetes and is characterized by disorders of insulin action and insulin secretion, either of which may be the predominant feature. Both are usually present at the time that this form of diabetes is clinically manifesting ${ }^{r}$. Most patients with this form of diabetes are obese, and obesity itself causes some degree of insulin resistance ${ }^{r}$.

Metformin is now established as a first-line antidiabetic therapy for the management of type $r$ diabetes ${ }^{\text {. }}$. Metformin mechanism of actions includes decreased glucose production in the liver, enhanced insulinstimulated glucose utilization in peripheral tissues (improved insulin sensitivity), particularly skeletal muscle, reduction of intestinal glucose absorption and apparently, increased insulin-stimulated glycogen synthesis (or reduced glycogenolysis). At the cellular level metformin facilitates glucose transport across membranes; apparently by stimulating glucose transporter activity ${ }^{\circ}$.Metformin may have special benefits in overweight patients with type $r$ diabetes. Unlike sulfonylureas, insulin, and thiazolidinediones, metformin does not affect body mass index (BMI) or decreases body weight in obese patients with and without diabetes ${ }^{\Upsilon,}$.

The peptide hormone ghrelin consisting of $Y \wedge$ amino acids including an O-n- octanoylated Ser $r$ residue (acylated ghrelin) which has been identified as an endogenous ligand for the growth hormone secretagogue receptor (GHSR) ${ }^{\wedge}$. This O-noctanoylated Ser $r$ residue is essential for ligand-receptor interaction. GHSR la is the only receptor specific for acylated ghrelin that has been identified ${ }^{9}$. Although ghrelin is synthesized in many tissues, including stomach, pancreas, cardiovascular tissue, hypothalamus, pituitary, kidney, and placenta $1 \cdot, 1,1,1,1 \leq$, the main source of plasma ghrelin is X/A-like cells localized in the oxyntic gland in the mucosa of the gastric fundus 10,17. Circulating ghrelin concentration has been shown to increase from early adulthood to middle age in humans and subsequently to decrease in old age in.

In addition to its GHstimulating action, many physiological functions of ghrelin have been revealed during the last decade, including the regulation of food intake, energy metabolism, gastrointestinal coordination, cell proliferation, apoptosis, cardiovascular function, and secretion of insulin and gut hormones ${ }^{q, 9, r \cdot, r)}$

The aim of this study is to investigate the effect of metformin on ghrelin serum level in type $r \mathrm{DM}$.

\section{Patients and method:}

The study was carried out in Al-Wafaa medical center for diabetic and endocrine disorder patients in Mosul from October $Y .11$ to March $r \cdot{ }^{\prime} r$. In this study 00 type $r$ diabetes mellitus patients and $r \cdot$ control healthy subjects had been participated. Those patients and subjects had been divided into \& groups:

1. Control healthy group: This group includes $r \cdot$ healthy subjects $(1 \cdot$ males and $1 \cdot$ females) who don't have any disease and do not take any medication. Those subjects are chosen from the medical staff of Al-Wafaa medical center for diabetic and endocrine disorders and college of dentistry and matched with other groups their ages ranges between $r$. 
and 70 years old with mean age of rq.70 1 ir.r r years.

r. Control diabetic patients group: This group was containing 10 type $r$ $\operatorname{DM}(\wedge$ males and $\checkmark$ females matched with other groups) who were newly diagnosed (from one to $\leq$ months) and they were not taking any medication yet and they were not suffering from any other diseases in addition to type $r$ DM.

r. Metformin $\bullet .$. mg group: This group includes $r$. type $r$ DM who were administered only $0 \cdot \mathrm{mg}$ of metformin daily in different durations.

£. Metformin 1... mg group: This group includes $r \cdot$ type $r$ DM who were administered only $1 \cdots \mathrm{mg}$ of metformin daily in different durations.

\section{Inclusion Criteria:}

Type $r$ diabetic patients who treated with metformin or newly diagnosed diabetic patients who didn't take any hypoglycemic medication yet.

\section{Exclusion Criteria:}

1. Patients with type 1 diabetes mellitus.

r. Patients taking insulin or oral hypoglycemic drugs other than glibenclamide, metformin.

r. Patients with renal or hepatic diseases.

£. Patients with myocardial infarction, angina, heart failure or high uncontrolled hypertension.

○. Pregnant and lactating women.

Blood samples had been collected from all subjects participated in this study in fasting condition and allowed to clot at room temperature

\section{Results:}

Table $r$ shows the demographic characteristic of subjects enrolled in this study. and then serum was separated by centrifugation for $1 \cdot$ minutes at ro.. rpm and the serum was divided into $r$ parts of.$\vee \circ \mathrm{ml}$ each, placed in a sterile eppendroff tubes of $1 .{ }^{\circ} \mathrm{ml}$ size and stored at $\left(-r \cdot{ }^{\circ} \mathrm{C}\right)$ in a deep freeze until the time of analysis ${ }^{r r}$. BMI had been calculated for each patient according to the equation ${ }^{r}$ : $\quad$ BMI $=$ weight $(\mathbf{k g}) /$ height $\left(\mathbf{m}^{r}\right)$ and then the patients were classified into $\leqslant$ groups:

Table !: NIH/NHLBI classification of BMI ${ }^{r \dot{r}}$

\begin{tabular}{||l|l|}
\hline BMI & Weight category \\
\hline Less than $1 \wedge .0 \cdot$ & Underweight \\
\hline $1 \wedge .0 \cdot-r \leq .9 \cdot$ & Normal weight \\
\hline$r_{0}-r 9.9 \cdot$ & Overweight \\
\hline$r \cdot$ and above & Obese \\
\hline
\end{tabular}

Fasting blood glucose was estimated by enzymatic method ${ }^{r \varepsilon}$ and also ghrelin serum level was estimated for each patient by enzyme linked immunosorbent assay using a technique called a quantitative sandwich immunoassay ${ }^{\text {ro }}$.

Statistical analyses of data were conducted using SPSS iv for windows software. A p-value of $\leq . .0$ was considered statistically significant. One-way ANOVA and Duncan's test were used to analyze the difference between the tested groups and also to analyze the difference within groups after dividing them into subgroups according to the dose and the duration of the treatment with metformin. Pearson correlations were used to evaluate correlations between parametric variables ${ }^{r q}$. 
Table r: Demographic characteristic of subjects enrolled in this study

\begin{tabular}{|c|c|c|c|c|c|c|c|c|c|}
\hline \multirow{2}{*}{\multicolumn{2}{|c|}{ Parameters }} & \multicolumn{2}{|c|}{$\begin{array}{c}\text { Control } \\
\text { healthy } \\
n=r\end{array}$} & \multicolumn{2}{|c|}{$\begin{array}{c}\text { Control diabetic } \\
\text { patients } \\
n=10\end{array}$} & \multicolumn{2}{|c|}{$\begin{array}{c}\text { Metformin } \\
\begin{array}{c}0 . \cdot \mathrm{mg} \\
n=r\end{array}\end{array}$} & \multicolumn{2}{|c|}{$\begin{array}{c}\begin{array}{c}\text { Metformin } \\
1 \ldots \mathrm{mg} \\
\mathrm{n}=r\end{array} \\
.\end{array}$} \\
\hline & & $\mathrm{n}$ & $\%$ & $\mathbf{n}$ & $\%$ & $\mathrm{n}$ & $\%$ & $\mathbf{n}$ & $\%$ \\
\hline \multirow[t]{2}{*}{$\operatorname{sex}$} & Male & 1. & $0 . \%$ & $1 \leqslant$ & $r \cdot \%$ & IT & $7 . \%$ & 9 & $\{0 \%$ \\
\hline & Female & 1. & $0 . \%$ & 7 & $V \cdot \%$ & $\Lambda$ & $\varepsilon . \%$ & 11 & $00 \%$ \\
\hline \multicolumn{2}{|c|}{ Age years } & \multicolumn{2}{|c|}{$\leqslant \varepsilon .70 \pm 9 . \wedge 7$} & \multicolumn{2}{|c|}{$\varepsilon \varepsilon . \varepsilon \cdot \pm 11 . \wedge \varepsilon$} & \multicolumn{2}{|c|}{$\leqslant 0.9 \cdot \pm \Lambda_{.} \cdot 1$} & \multicolumn{2}{|c|}{$\Sigma \Lambda .90 \pm \Lambda . \mu r$} \\
\hline \multicolumn{2}{|c|}{ BMI kg/m } & \multicolumn{2}{|c|}{$r \cdot r \varepsilon \pm r . r V$} & \multicolumn{2}{|c|}{$r \cdot . \wedge \cdot \pm 0.0}$. & \multicolumn{2}{|c|}{$r \cdot .9 \cdot \pm r .0 \cdot$} & \multicolumn{2}{|c|}{$r$ r.A. $\pm \varepsilon . r}$. \\
\hline
\end{tabular}

* Age and BMI were presented as mean $\pm \mathrm{SD}$.

Table ${ }^{r}:$ Comparison among parameters in all tested groups:

\begin{tabular}{|c|c|c|c|c|c|}
\hline Parameters & $\begin{array}{c}\text { Control } \\
\text { healthy } \\
n=r .\end{array}$ & $\begin{array}{c}\text { Control } \\
\text { diabetic } \\
\text { patients } \\
n=10\end{array}$ & $\begin{array}{c}\text { Metformin } \\
\qquad \ldots \mathrm{mg} \\
n=r .\end{array}$ & $\begin{array}{c}\begin{array}{c}\text { Metformin } \\
1 \ldots \mathrm{mg} \\
\mathrm{n}=r .\end{array} \\
.\end{array}$ & p-value \\
\hline FBS mg/dl & $\begin{array}{c}97 \pm 7 \\
\mathrm{~A}\end{array}$ & $\begin{array}{c}Y \cdots \pm V V \\
B\end{array}$ & $\begin{array}{c}1 \wedge r \pm V \tau \\
B\end{array}$ & $\begin{array}{c}111 \pm 09 \\
B\end{array}$ & $\because \cdots$ \\
\hline $\begin{array}{c}\text { Ghrelin } \\
\text { serum level } \\
\text { ng/ml } \\
\end{array}$ & $\begin{array}{c}1 r^{\prime} \cdot \Lambda \pm 0 . r_{0} \\
A B\end{array}$ & $\begin{array}{c}\Lambda . V \leq \pm Y . Y Y \\
A\end{array}$ & $\begin{array}{c}\mu . \neg \mu \pm \wedge . \wedge \\
\mathrm{AB}\end{array}$ & $\begin{array}{c}|Y . T \cdot \pm| Y . \wedge \mid \\
B\end{array}$ & $\cdot Y \cdot V$ \\
\hline BMI kg/m & $\begin{array}{c}r \cdot r \leqslant \pm r . r V \\
A\end{array}$ & $\begin{array}{c}r \cdot . \wedge \cdot \pm 0.0 \cdot \\
\mathrm{A}\end{array}$ & $\begin{array}{c}r \cdot .91 \pm r .0 \cdot \\
\mathrm{A}\end{array}$ & $\begin{array}{c}r Y . \wedge \cdot \pm \varepsilon . Y \wedge \\
A\end{array}$ & GYY \\
\hline Age years & $\begin{array}{c}\varepsilon \leqslant .70 \pm 9.17 \\
A\end{array}$ & $\begin{array}{c}\varepsilon \varepsilon . \varepsilon \cdot \pm 11 . \wedge \varepsilon \\
A\end{array}$ & $\begin{array}{c}\varepsilon 0.9 \cdot \pm \wedge . \cdot 1 \\
A\end{array}$ & $\begin{array}{c}\varepsilon \wedge .90 \pm \lambda . r \mu \\
A\end{array}$ & $. \leqslant T \leqslant$ \\
\hline
\end{tabular}

*Different letters horizontally means significant difference at $\mathbf{P}<\because$. $\bullet$ between tested groups by Duncan's test.

* FBS= Fasting blood sugar.

* Age, BMI and ghrelin serum level were presented as mean $\pm \mathrm{SD}$.

Table $r$ shows significant lower level in FBS in control healthy group when compared with the other three diabetic patients groups with or without metformin therapy at $\mathrm{P}<\cdot . \bullet$.

Ghrelin serum level in control diabetic patients is lower when compared to that of control healthy group while it is higher in diabetic patients' group using metformin $0 .$. mg daily when compare with control diabetic patients group but there is no significant difference. There is significant difference in ghrelin serum level between control diabetic patients group and diabetic patients' group using metformin $1 \cdots \mathrm{mg}$ daily at $\mathrm{P}<$ $\because{ }^{\circ}$. (Table ${ }^{r}$ ) 
Table :: The effect of metformin duration of usage on ghrelin serum level in diabetic patients groups using metformin

\begin{tabular}{|c|c|c|c|c|}
\hline Parameters & $\begin{array}{c}-1 \text { months } \\
\text { (1) }\end{array}$ & $\begin{array}{c}\tau-1 Y \text { months } \\
(r)\end{array}$ & $\begin{array}{c}>1 Y \text { months } \\
(r)\end{array}$ & p-value \\
\hline FBS mg/dl & $179 \pm 7 \varepsilon$ & $1 \wedge r \pm 7 \varepsilon$ & $191 \pm V 7$ & $.0 \leqslant \leqslant$ \\
\hline $\begin{array}{c}\text { Ghrelin serum } \\
\text { level } \mathbf{n g} / \mathrm{ml}\end{array}$ & $\mid r . \top \Lambda \pm \nearrow . r \Lambda$ & IV.rV $\pm V .77$ & $1 V . \cdot 1 \pm 9 . V 7$ & $\cdot V \cdot r$ \\
\hline BMI kg/m & $r . \wedge r \pm \varepsilon .0$ & $r . \cdot r \pm r .9 r$ & $M Y_{. V Y} \pm \varepsilon . V$ & .071 \\
\hline
\end{tabular}

Table $\left\{\right.$ shows that ghrelin serum level is higher in the $r^{\text {nd }} \uparrow$ months and after ir months of treatment in comparison to the $1^{\text {st }} \uparrow$ months of treatment.

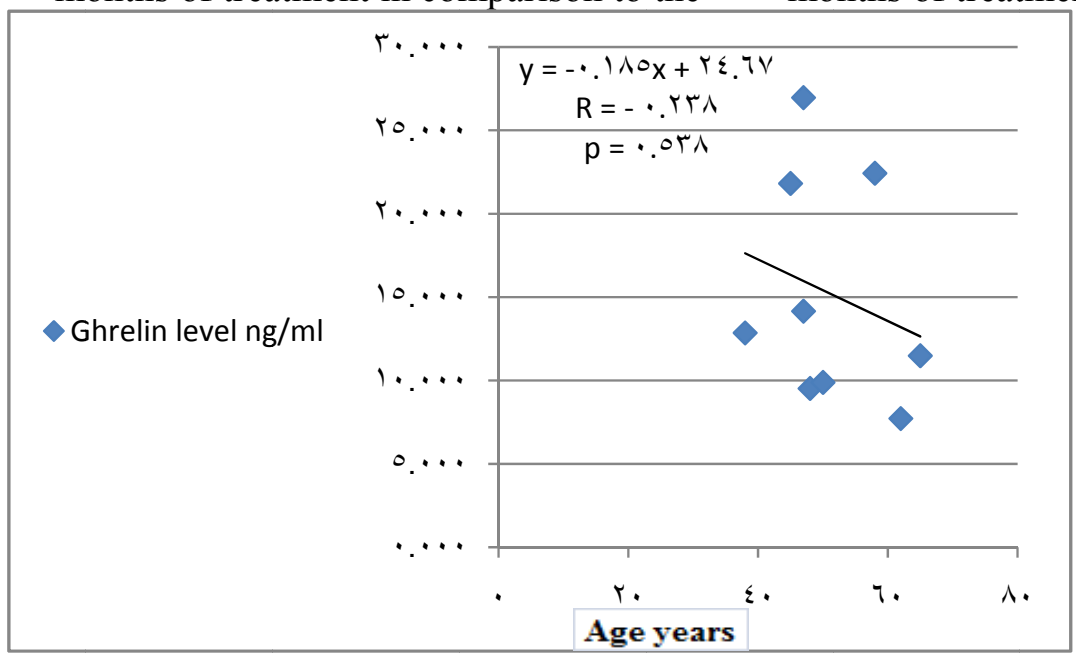

Figure 1: Correlation between ghrelin serum level and age in healthy subjects with ages more than $r$. years old.

Figure 1 shows a negative correlation between ghrelin serum level and age in healthy subjects with ages more than $r \cdot$ years old.

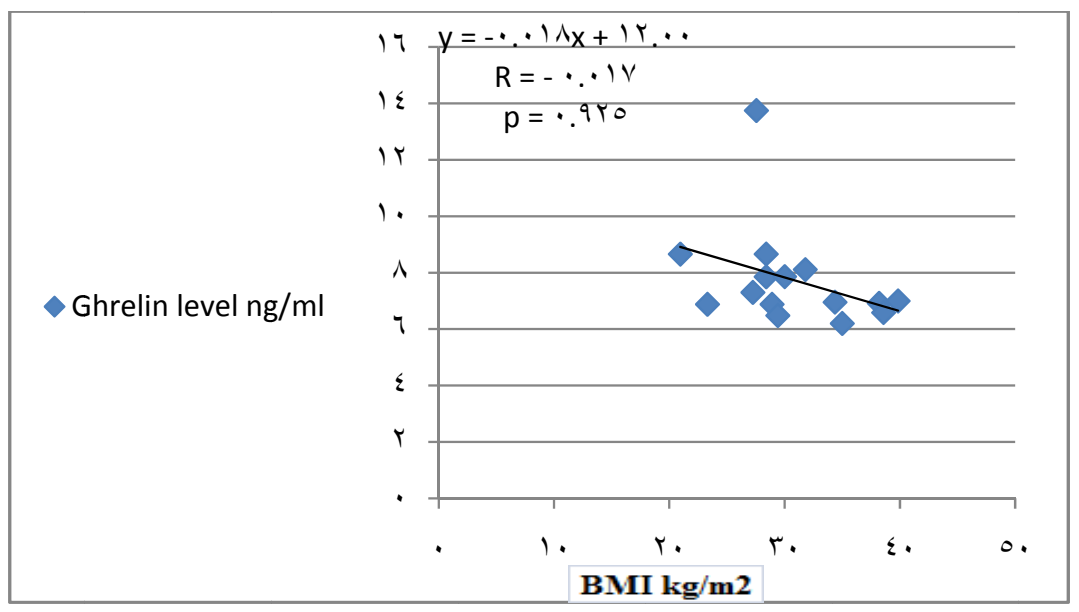

Figure $r$ : Correlation between ghrelin serum level and BMI in healthy subjects.

Figure $r$ shows negative correlation between ghrelin serum level and BMI in healthy subjects. 


\section{Discussion:}

Ghrelin stimulates insulin release in the presence of high levels of glucose (^.r $\mathrm{mM}$ ) that could independently cause insulin release and increase insulin sensitivity I\&. In contrast, ghrelin had no effect on insulin release in the context of a basal level of glucose $(\uparrow . \wedge \mathrm{mM})$. On the other hand, ghrelin reduces insulin secretion and induces hyperglycaemia in humans in the presence of low levels of glucose ${ }^{r v}$ Administeration of ghrelin intravenously at low concentrations was shown to decrease glucose induced insulin secretion of isolated pancreatic islets in vitro, while supraphysiological ghrelin concentrations had an opposite effect on insulin secretion ${ }^{r \wedge}$.

According to this ghrelin is important to achieve a good glycemic control in both hypo and hyper glycemia. In this study ghrelin serum level in diabetic patients is tends to be lower ( $. \vee \Sigma \pm$ Y.r $Y$ ng/ml) when compared with healthy subjects ( 1 r. $\cdot \wedge$ \pm 0. ro $\mathrm{ng} / \mathrm{ml}$ ). Also low ghrelin serum level is usually associated with insulin resistance ${ }^{r q}$. Leena et al. $(r \cdot 1 \cdot)^{r}$. indicated that circulating ghrelin concentrations are reduced in healthy offspring of type $r$ diabetic patients indicating the presence of possible genetic component in the regulation of ghrelin plasma levels. Pöykkö et al. $(r \ldots r)^{r}$ showed that fasting plasma concentrations of total ghrelin were lower among subjects with type $r$ diabetes compared to those without the disease. The difference remained significant even when age, sex and BMI were taken into account in multivariable models. . In addition, Adelino and Joa o-Bruno, $(r \cdot . v)^{r r}$ indicated that low ghrelin levels are associated with insulin resistance, hypertension and the prevalence of type $r$ diabetes; polymorphisms of the ghrelin gene are associated with the risk of diabetes because ghrelin promotes regeneration of $\beta$-cells preventing the development of diabetes in disease-prone animals after $\beta$-cell destruction. Furthermore, ghrelin is shown to prevent cell death and apoptosis of HIT-T 10 pancreatic $\beta$-cell line ${ }^{r r}$. This low ghrelin serum level could be one of the pathophysiological reasons of DM.

Patients using metformin $\mathrm{O.}$ mg daily in this study have higher ghrelin serum level (Ir.Tr $\pm \wedge . \wedge$. $\mathrm{ng} / \mathrm{ml}$ ) when compared with diabetic patients group who did not take any medication yet $(\wedge . \vee \leqslant \pm r . r r \mathrm{ng} / \mathrm{ml})$ but there is no significant difference while there is significant difference in ghrelin serum level between patients using metformin $1 \cdots$ mg daily (IV.T. \pm Ir.AI) and diabetic patients group who did not take any medication yet $(\wedge . \vee \leq \pm$ r. Y r ng/ml) as appeared in table $r$. According to this; elevation of ghrelin level could be one of the mechanisms by which metformin increase insulin sensitivity and produce a better glycemic control.

Ghrelin serum level tend to be higher in the patients using metformin in the rnd six months ( $Y . r V \pm V . T 7)$ group and in patients using metformin for more than one year $(\mid \vee . \cdot 1 \pm 9 . \vee \tau)$ when compared with ghrelin serum level in the patients using metformin in the 'st six months ( $Y.\urcorner \wedge \pm \Upsilon . Y \wedge)$ as appeared in table $r$. So, ghrelin serum level elevating action of metformin increased with time in the 'st year of treatment. Bray et al $(r \cdot 1 r)^{r \varepsilon}$ mentioned that metformin induced weight loss caused by anorexia is usually happened in the $1^{\text {st }} r$ months of treatment while Generali and Cada $(r \cdot r)^{r_{0}}$ mentioned that it is usually happened in the $1^{\text {st }} 7$ months of treatment. As appeared in table \& 
ghrelin serum level tend to be lower in the $1^{\text {st }} r$ months group than the other $r$ groups which could explain the reason behind the less appetite and weight loss that accompanied metformin usage even though it is still higher than that of control disease group so, how metformin can cause weight loss while it increases the hunger hormone (ghrelin). English et al $(r \ldots V)^{r r}$ mentioned that metformin therapy was found to prolong the postprandial fall in total plasma ghrelin levels, and thus had concomitant effects on appetite in type $r \mathrm{DM}$ and decreasing the number of meals during the day contributing to its actions in promoting weight loss and attenuating weight gain in these patients.

Figure 1 shows a negative correlation between ghrelin serum level and age in healthy subjects with ages more than $r$. years old and this is mentioned in Kozakowski $\mathrm{J}$ et al $(r \cdots \wedge)^{r v}$.So, ghrelin tend to decreased with age, therefore; elderly subjects usually have lower ghrelin serum level when compared with young age subjects which could explain why type $r$ DM usually appear in older individuals ${ }^{r}$.

Figure $r$ shows negative correlation between ghrelin serum level and BMI in healthy subjects so, obese subjects have lower ghrelin serum level than in normal subjects ${ }^{r \wedge}$ and this could explain the reason behind insulin resistance in obese patients with type ${ }^{r} \mathrm{DM}^{r}$.

\section{Conclusion:}

Ghrelin is important to achieve a good glycemic control in both hypo and hyper glycemia. Ghrelin serum level in diabetic patients is tends to be lower when compared with healthy subjects. Metformin increase ghrelin serum level in diabetic patients and this could be one of the mechanisms by which metformin increase insulin sensitivity and produce a better glycemic control. Elevation of ghrelin serum level in diabetic patients by metformin increased with dose and also increased with duration. Higher age and BMI negatively affect ghrelin serum level which in turn could explain the higher prevalence of DM in older subjects with higher BMI.

\section{References}

1. Reinauer H, Home PD, Kanagasabapathy AS, Heuck C. Laboratory Diagnosis and Monitoring of Diabetes Mellitus. WHO Y..r.

r. Alberti KGMM, Zimmet PZ. Definition, diagnosis and classification of diabetes mellitus and its complications. Part 1: diagnosis and classification of diabetes mellitus. Provisional report of a WHO Consultation. Diabetic Medicine 1991; 10: or9_oor.

$r$. American Diabetes Association, Diabetes Care

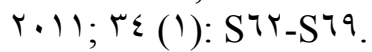

£. Scarpello JHB, Howlett HCS. Metformin therapy and clinical uses. Diabetes and Vascular Disease Research Y... ; 0: 1 $0 Y$.

- Deruiter J. Overview of the antidiabetic agents Endocrine. Pharmacotherapy Module r...r; 1:1-rr.

7. Pasquali R, Gambineri A, Biscotti D et al. Effect of longterm treatment with metformin added to hypocaloric diet on body composition, fat distribution, and androgen and insulin levels in abdominally obese women with and without the polycystic ovary syndrome. J Clin Endocrinol Metab Y...; No:YVTV_YVV

v. Kirpichnikov D, McFarlane SI, Sowers JR. Metformin: An Update. Ann Intern Med Y..r; IrV:YO-rr. 
^. Kojima M, Hosoda H, Date Y et al. Ghrelin is a growthhormone-releasing acylated peptide from stomach. Nature 1999; \&.r: 707_77.

१. Kojima M, Kangawa K. Ghrelin: structure and function. Phys Rev Y...0; 10: క90_orr.

1. Mori K, Yoshimoto A, Takaya $\mathrm{K}$ et al. Kidney produces a novel acylated peptide, ghrelin. FEBS Letters $r . . . ;$; $\leqslant$ ฯ r r r YIT.

1). Gualillo O, Caminos J, Blanco $M$ et al. Ghrelin, a novel placental-derived hormone. Endocrinology $r . .1$; $1 \leqslant r_{\text {: }} \vee \wedge \Lambda$ $\vee 9 \leq$.

Ir. Hattori N, Saito T, Yagyu T et al. Growth hormone (GH), GH receptor, $\mathrm{GH}$ secretagogue receptor, and ghrelin expression in human $\mathrm{T}$ cells, B cells, and neutrophils. J Clin Endocrinol Metab Y... ; ᄉ : $\{r \wedge \varepsilon+\varepsilon r q 1$.

1r. Korbonits M, Bustin SA, Kojima $\mathrm{M}$ et al. The expression of the growth hormone secretagogue receptor ligand ghrelin in normal and abnormal human pituitary and other neuroendocrine tumors. J Clin Endocrinol Metab Y...; $\wedge$ \%: $\wedge \wedge)-\Lambda \wedge V$.

I . Date $Y, \quad$ Nakazato $M$, Hashiguchi $\mathrm{S}$ et al. Ghrelin is present in pancreatic $\alpha$-cells of humans and rats and stimulates insulin secretion. Diabetes $r \ldots r ; 01: 1 r \varepsilon-1 r 9$.

10. Date Y, Kojima M, Hosoda H et al. Ghrelin, a novel growth hormone-releasing acylated peptide, is synthesized in a distinct endocrine cell type in the gastrointestinal tracts of rats and humans. Endocrinology

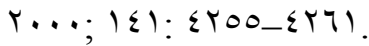

17. Hosoda H, Kojima M, Matsuo $\mathrm{H}$ et al. Ghrelin and des-acyl ghrelin: two major forms of rat ghrelin peptide in gastrointestinal tissue. Bioch Biophys Res Commu r...; rVq: 9.9-9ाr.

IV. Cummings DE, Purnell JQ, Frayo RS et al. A preprandial rise in plasma ghrelin levels suggests a role in meal initiation in humans. Diabetes Y...; 0.:IVI $\leq-|V| 9$.

1^. Rigamonti AE, Pincelli AI, Corra B et al. Plasma ghrelin concentrations in elderly subjects: comparison with anorexic and obese patients. J Endocrinol $r . . . r$; IVo: 1_o.

19. Nakazato M, Murakami N, Date $\mathrm{Y}$ et al. A role for ghrelin in the central regulation of feeding. Nature $Y . \cdot$; $\leqslant . q$ : $19 \leqslant-191$

$r \cdot$ Nakahara K, Nakagawa $M$, Baba Y et al. Maternal ghrelin plays an important role in rat fetal development during pregnancy. Endocrinology

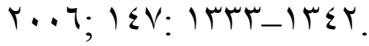

r). Zhang M, Yuan F, Liu H et al, Inhibition of proliferation and apoptosis of vascular smooth muscle cells by ghrelin. Acta Bioch Y...A; $\varepsilon \cdot:$ Vฯq_VVฯ.

rr. Pagana KD, Pagana TJ. Mosby's Manual of Diagnostic and Laboratory Tests. rrd ed. Mosby Elsevier; $r ..\urcorner . ~|r-r| p$.

$r$ r. NIH/NHLBI (National Institutes of Health, National Heart, Lung, and Blood Insitute), Clinical Guidelines on the Identification, Evaluation and Treatment of Overweight and Obesity in Adults. U.S. Department of Health and Human Services, Public Health Service, 1991

$r$ \&. Kabasakalian $\mathrm{P}$, Kalliney $\mathrm{S}$, Westcott A. Enzymatic Blood Glucose Determination by Colorimetry of N, NDiethylaniline- - $_{-}$ 
Aminoantipyrine. Clin. Chem $19 \vee \leqslant ; Y \cdot(0): 7 \cdot 7 \_$T.V.

ro. Prudom C, Liu J, Patrie J et al. Comparison of Competitive Radioimmunoassays and TwoSite Sandwich Assays for the Measurement and Interpretation of Plasma Ghrelin Levels. J Clin Endocrinol Metab Y.l.; 90(0): YrOL_rroN.

Yฯ. Howitt D, Cramer D. A guide to computing stastics with SPSS for windows ${ }^{\text {tm }} r^{\text {nd }}$ ed. Pearson Education Limited, Essex. England; 1999.

Yv. Broglio F., Arvat E., Benso A. et al. Ghrelin, a natural Gh secretagogue produced by the stomach, induces hyperglycemia and reduces insulin secretion in humans. J. Clin. Endocrinol. Metab. Y..';

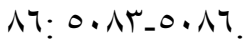

r^. Salehi A, Dornonville de la Cour C, Håkanson $\mathrm{R}$ et al. Effects of ghrelin on insulin and glucagon secretion: a study of isolated pancreatic islets and intact mice. Regul Pept ${ } \ldots \varepsilon$; 1) $(r): 1 \leqslant r-10$.

หq. R. Barazzoni, M. Zanetti, C. Ferreira et al. Relationships between desacylated and acylated ghrelin and insulin sensitivity in the metabolic syndrome. J Clin Endocrinol Metab r...v; qr: rqro_rq . .

$r \cdot$ Leena P., Olavi Ukkola, Marjukka Kolehmainen et al.. Ghrelin in Diabetes and Metabolic Syndrome. International Journal of Peptides $r_{\cdot} \cdot 1 \cdot ; r_{\text {: }} r_{-} \varepsilon$.

ऍ. Pöykkö S, Ukkola O, Kauma H et al. Ghrelinarg ${ }^{\circ}$ ) gln mutation is a risk factor for type $r$ diabetes and hypertension in a random sample of middle-aged subjects. Diabetologia r..r; $\leqslant 7(\varepsilon)$ : $\{00-\varepsilon 01$. rr. Adelino F. Leite-Moreira and Joa o-Bruno Soares. Physiological, pathological and potential therapeutic roles of ghrelin, Drug Discovery Today Y..V; Ir:YVV-rVq.

r. R. Granata, F. Settanni, L. Trovato, et al. Unacylated as well as acylated ghrelin promotes cell survival and inhibit apoptosis in HITT 10 pancreatic beta cells. J Endocrinol Invest $r \ldots r ; r q$ : IYO-l s.

rะ. Bray GA., Edelstein SL., Crandall JP et al. Long-Term Safety, Tolerability, and Weight Loss Associated With Metformin in the Diabetes Prevention Program Outcomes Study. Diabetes Care r. Ir; ro: VTI_VTr.

ro. Generali J., Cada DJ. Metformin: Weight Loss (Antipsychotic-Induced

Weight Gain). Hospital Pharmacy $r . . r$; $r v$ : Ir^q Irqs.

r.. English PJ, Ashcroft A, Patterson $\mathrm{M}$ et al. Metformin prolongs the postprandial fall in plasma ghrelin concentrations in type $r$ diabetes. Diabetes Metab Res Rev r...v; rr:rqq_ r.r.

rv. Kozakowski J, Rabijewski M \& Zgliczyński W. Ghrelin growth hormone releasing and orexigenic hormone in men declines with age, insulin and with decrease in testosterone concentration. Neuro Endocrinol Lett $r \ldots \wedge ; r q(1)$ : $1 \cdot \cdot-1 \cdot 7$.

ז^. Bellone S, Rapa A, Vivenza D et al. Circulating ghrelin levels as function of gender, pubertal status and adiposity in childhood. J Endocrinol Invest r...r; ro: $1 r_{-} 10$. 